\title{
Office-Based Preventive Dental Program and Statewide Trends in Dental Caries
}

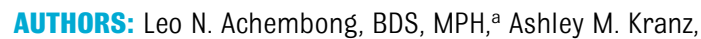
$\mathrm{PhD},{ }^{\mathrm{b}}$ and R. Gary Rozier, DDS, MPH ${ }^{\mathrm{c}}$

aOral Health Section, Division of Public Health, North Carolina Department of Health and Human Services, Raleigh, North Carolina; and bental Research, School of Dentistry, and ${ }^{c}$ Department of Health Policy and Management, Gillings School of Global Public Health, University of North Carolina at Chapel Hill, Chapel Hill, North Carolina

\section{KEY WORDS}

primary care, early childhood, dental caries, prevention, fluoride varnish

\section{ABBREVIATIONS}

$\mathrm{Cl}$-confidence interval

$\mathrm{dmft}$ - decayed, missing, and filled teeth

IMBP - Into the Mouths of Babes Program

NSLP-National School Lunch Program

OLS—ordinary least squares

Dr Achembong designed the study and drafted the initial manuscript; Dr Kranz did the statistical analysis, assisted with result interpretation, and critically revised the initial manuscript; Dr Rozier conceptualized and designed the study, supervised the study conduct, assisted with data analysis, and critically revised the initial manuscript; and all authors approved the final manuscript as submitted.

www.pediatrics.org/cgi/doi/10.1542/peds.2013-2561

doi:10.1542/peds.2013-2561

Accepted for publication Jan 22, 2014

Address correspondence to Leo N. Achembong, BDS, MPH, North Carolina Oral Health Section, 1910 Mail Service Center, Raleigh, NC 27699-1910. E-mail: achembong@yahoo.com

PEDIATRICS (ISSN Numbers: Print, 0031-4005; Online, 1098-4275). Copyright (C) 2014 by the American Academy of Pediatrics FINANCIAL DISCLOSURE: The authors have indicated they have no financial relationships relevant to this article to disclose.

FUNDING: Funded by a Dental Public Health Training Grant from the Health Resources and Services Administration (grant D13HP15295)

POTENTIAL CONFLICT OF INTEREST: The authors have indicated they have no potential conflicts of interest to disclose.
WHAT'S KNOWN ON THIS SUBJECT: Guidelines recommend that primary care physicians provide preventive dental services to young children. Most state Medicaid programs reimburse physicians for providing fluoride varnish. Individual-level studies show that these services are effective in reducing caries-related treatments and costs.

WHAT THIS STUDY ADDS: Preventive dental services provided through a North Carolina Medicaid preventive dental program led to a reduction in dental caries among young children statewide. Programs targeting vulnerable populations through medical offices can reduce disparities in oral health among preschoolaged populations.

OBJECTIVES: To evaluate the impact of a North Carolina Medicaid preventive dentistry program in primary care medical offices (Into the Mouths of Babes Program [IMBP]) on decayed, missing, and filled teeth (dmft) of kindergarten students statewide and in schools with a large proportion of students from low-income families.

METHODS: An ecologic study using panel data of 920505 kindergarten students with 11694 school-year observations examined the effect of the IMBP on dmft scores from 1998 to 2009. Ordinary least squares regression with fixed effects determined the association between IMBP visits per child 0 to 4 years of age per county and mean dmft scores per kindergarten student per school, controlling for schoollevel poverty and ethnicity, county-level Medicaid enrollment, and supply of dentists and physicians.

RESULTS: Mean dmft per kindergarten student per school increased from 1.53 in 1998 to 1.84 in 2004, then decreased to 1.59 in 2009. The mean number of IMBP visits per child 0 to 4 years of age per county increased from 0.01 in 2000 to 0.22 in 2009. A 1-unit increase in IMBP visits per county was associated with a 0.248 ( $95 \%$ confidence interval, -0.40 to -0.10 ) decrease in $\mathrm{dmft}$ per kindergarten student per school. For schools with more students at high risk for dental disease, a 1-unit increase in IMBP visits was associated with a 0.320 (95\% confidence interval, -0.55 to -0.09 ) decrease in $\mathrm{dmft}$.

CONCLUSIONS: IMBP reduced dental caries among targeted vulnerable children, which helped reduce oral health disparities among preschoolaged children in North Carolina. Pediatrics 2014;133:e827-e834 
The 2010 Global Burden of Disease Study reported untreated dental caries in permanent teeth to be the most common problem worldwide and in primary teeth to be the 10th most common problem among 291 diseases and injuries evaluated. ${ }^{1}$ In the United States, $33 \%$ of 3 - to 5 -year-old children experienced dental caries in at least 1 primary tooth in 1999 to 2004, an increase in prevalence since the previous national survey. ${ }^{2,3}$ Children from low-income and minority families are most affected. ${ }^{4}$ Caries causes pain and infection, leading to high treatment costs and reduced quality of life..$^{5-7}$ Death can result, particularly from use of general anesthesia often needed for treatment of children who are young, have severe disease, or have special health care needs. ${ }^{8}$

Dental disease and workforce assessments in North Carolina confirm that national observations about disparities in dental caries can be extended to the state. ${ }^{9-12}$ Some state indicators were found to be worse than national estimates, particularly use of preventive and treatment services by young children enrolled in Medicaid. The rural nature of North Carolina, coupled with an increasing low-income population and an uneven distribution, if not undersupply, of dentists statewide, were clear markers for disparities in oral health.

In response to the growing public health problem in North Carolina, in 2000 the state Medicaid program began the Into the Mouths of Babes Program (IMBP), in which preschool-aged children could receive preventive dental care during medical office visits. ${ }^{13}$ In this program, Medicaid reimburses nondental health care providers for up to 6 medical visits in which preventive dental services (child screening and risk assessments, application of fluoride varnish, and parent oral health counseling) are provided for children $3 \frac{1}{2}$ years of age and younger. During its first 11 years, children had more than a million preventive dental visits in medical offices. By 2011, 80 000 children were receiving services annually. ${ }^{12}$

The primary goals of the IMBP are to increase access to preventive dental services for high-risk infants and toddlers, thus reducing the prevalence of dental caries and narrowing the gap in oral health disparities. Individual-level studies demonstrate that the IMBP is effective in increasing access to preventive dental care and improving oral health outcomes for those who receive services. ${ }^{14-16}$ The purpose of this study is to determine the impact of the IMBP, a statewide program targeting young children enrolled in Medicaid who use primary care medical services, on trends in dental caries among 5-yearold children. We anticipate a measurable population effect at the community level from providing IMBP services to low-income children who are most affected with dental caries, thus helping to reduce the disparities in oral health.

\section{METHODS}

\section{Overview of Research Design}

This ecologic study used panel data and regression methods to examine the association between IMBP services provided in each county and caries experience of kindergarten children in North Carolina for academic years 1998-1999 to 20092010, by using schools as the unit of analysis. We estimated regression models including all schools and only a subset of schools in which students were considered to be at high risk for dental disease. This study was determined by the North Carolina Division of Public Health Institutional Review Board for the Health and Safety of Human Subjects to be exempt from full review.

\section{Data Sources and Variables}

\section{Outcome Variable}

Annual estimates for caries experience were derived from the oral health surveillance system maintained by the state dental public health program. ${ }^{17}$ School-level files provide summary counts of decayed, missing, and filled teeth (dmft) of kindergarten students, a well-accepted measure of lifetime caries experience. Evaluation of examiner performance has demonstrated reliability and validity for these estimates, ${ }^{18}$ and data have been used in a number of research studies. ${ }^{19-21}$ For this study, the unit of analysis was the school year, and caries experience was measured as the school-level average number of dmft per screened kindergarten student.

\section{Main Explanatory Variable}

Data for the annual number of IMBP visits for each county were derived from reports produced by the state Medicaid program since inception of the IMBP in $2000 .{ }^{22}$ They provide a count of visits based on Medicaid payment of nondental providers for delivery of a specified set of bundled oral health services (screening and risk assessment, counseling, fluoride varnish application). We constructed our exposure variable to be a county-level measure of the mean number of IMBP visits per child 0 to 4 years of age per year. Because IMBP services are provided to children aged 0 to $3 \frac{1}{2}$ years and outcomes are assessed in children at 5 years of age, this variable was lagged 3 years.

\section{Control Variables}

Two school-level control variables included in the analysis were annual measures of the percentage of kindergarten students who were Hispanic ${ }^{23}$ and percentage of students enrolled in the National School Lunch Program (NSLP), a valid measure of poverty. ${ }^{24,25}$ Additionally, 3 county-level control variables measured the annual number of dentists per 10000 population, ${ }^{26}$ number of physicians per 10000 population, ${ }^{26}$ and percentage of children 0 to 21 years of age enrolled in Medicaid. ${ }^{27,28}$ 


\section{Analysis Strategy}

We calculated descriptive statistics for all variables and all years. Preliminary bivariate analyses examining associations between each predictor variable and school-level average dmft were conducted using ordinary least squares (OLS) regressions with $t$ tests, without adjustment for other variables.

We used OLS regression models, adjusting for the primary explanatory variable and all control variables, to estimate the effect of the IMBP on the school-level average number of dmft per kindergarten student. ${ }^{29}$ The outcome of interest was weighted by the number of students in the school who were screened. Because we had repeat observations of schools over time, school-level fixed effects adjusted for school characteristics that were constant over time and year fixed effects adjusted for statewide time-varying trends. To account for potential correlation between schools' variance estimates over time, we used cluster-robust SEs.30 Wald tests were used to examine associations between explanatory variables and the outcome variable.

OLS regression models were estimated for the full sample and for a subgroup of schools that had $\geq 80 \%$ of their students participating in the NSLP at any point during the study period. We hypothesized that the effect of the IMBP would be greater in schools with a large percentage of students from low-income families because they would have more students enrolled in Medicaid and thus eligible for and using Medicaid preventive dental services.

We ran simulations by using coefficients from the regression models to calculate the predicted school-level average number of dmft per kindergarten student in 2009 under the following 3 conditions: no IMBP, the observed number of IMBP visits, and more IMBP visits. To understand how increasing the number of IMBP visits might reduce dental caries in young children, we predicted mean dmft in 2009 based on increases in the mean number of IMBP visits per county over the base rate of 2823 visits ( 0.18 visits per 0 - to 4-yearold child per county) by 500, 1000, 2000 , and 4000 visits, representing, respectively, an average number of visits per county for the child population 0 to 4 years of age of $0.22,0.26$, 0.31 , and 0.45 . All analyses and statistical tests were performed in Stata/IC 12 (Stata Corp, College Station, TX) at a .05 significance level.

\section{RESULTS}

\section{Sample}

Oral health surveillance data were available for schools in all of the state's 100 counties during 1998-1999 to 20012002 and 2003-2004 to 2009-2010. The surveillance database included 12256 school-year observations (1385 unique schools) and 1031208 kindergarten students (mean per year $=93$ 922), of whom 965867 (93.6\%; mean per year = $87956)$ were screened. We excluded schools missing information about NSLP participation $(n=12)$, with 5 or fewer kindergarten students screened $(n=3)$, missing information about Hispanic ethnicity $(n=9)$, and with surveillance data for 1 year only $(n=41)$.

The analytical sample included 11694 school-year observations (1294 unique schools) and 1011263 students (mean per year $=92163)$, of whom 946911 (93.6\%; mean per year $=86$ 291) were screened. Schools were included in the analysis for an average of 9.89 years. The subgroup analysis of schools that ever had $80 \%$ or more of their students participating in the NSLP had 4236 school year-observations for 448 schools, included for an average of 10 years.

\section{Descriptive Statistics}

Table 1 provides descriptive statistics for each year and for all variables included in the study. Mean dmft per kindergarten student per school increased from $1.53(S D=0.69)$ in 1998 to $1.84(S D=0.75)$ in 2004 , then decreased to $1.59(S D=0.77)$ in 2009. The mean number of IMBP visits per child aged 0 to 4 years per county increased from 0.01 $(S D=0.03)$ in the first year of the program to 0.22 (SD = 0.14) in 2009 (Fig 1).

\section{Regression Results}

Table 2 displays the adjusted coefficients from the OLS regression models examining the association of each variable with the school-level average number of dmft per kindergarten student for the full sample and the subsample of high-risk schools. In the full sample, we observed a statistically significant negative association between IMBP visits and the school-level average number of $\mathrm{dmft}$ per student. An increase in the average number of IMBP visits per child aged 0 to 4 years per county by 1 unit was associated with a 0.25 (95\% confidence interval [CI], -0.40 to -0.09 ) decrease in the annual school-level average number of dmft per kindergarten student.

Approximately $35 \%$ of schools had $80 \%$ or more of their students participating in the NSLP. Among these schools, the magnitude of the association between IMBP visits and dmft was greater than for all schools. An increase in the average number of IMBP visits per child aged 0 to 4 years per county by 1 unit was associated with a $0.32(95 \% \mathrm{Cl}$, -0.55 to -0.09 ) decrease in the annual school-level average number of dmft per kindergarten student.

Using coefficients from the regression models, we ran simulations to calculate the predicted school-level average number of dmft per kindergarten student, under 6 different scenarios of IMBP implementation (Table 3). In the full sample of schools, the predicted mean $\mathrm{dmft}$ in 2009 was greatest assuming no IMBP implementation (1.45; 95\% Cl, 1.39 to 1.50). Increasing the school-level 


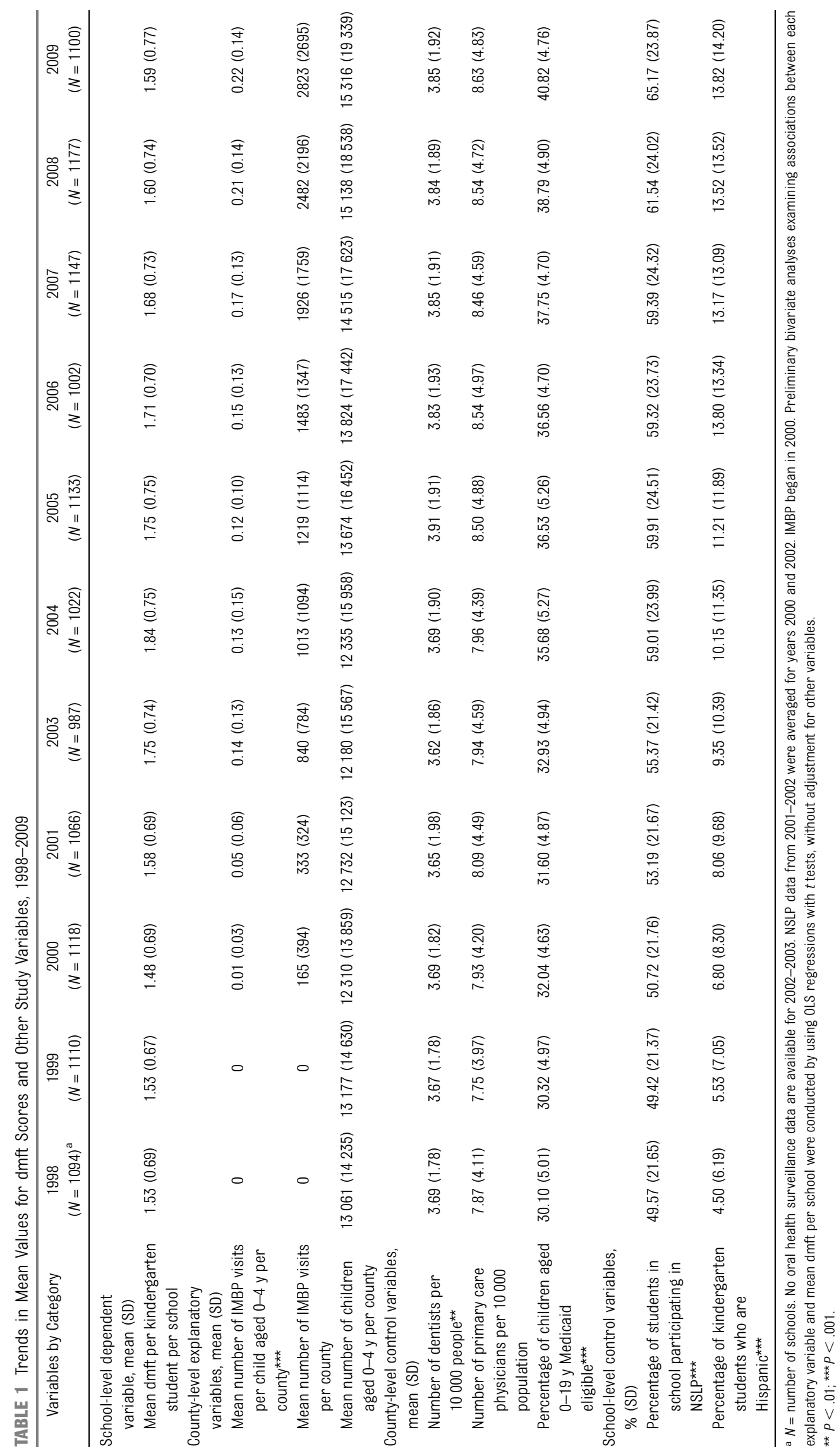




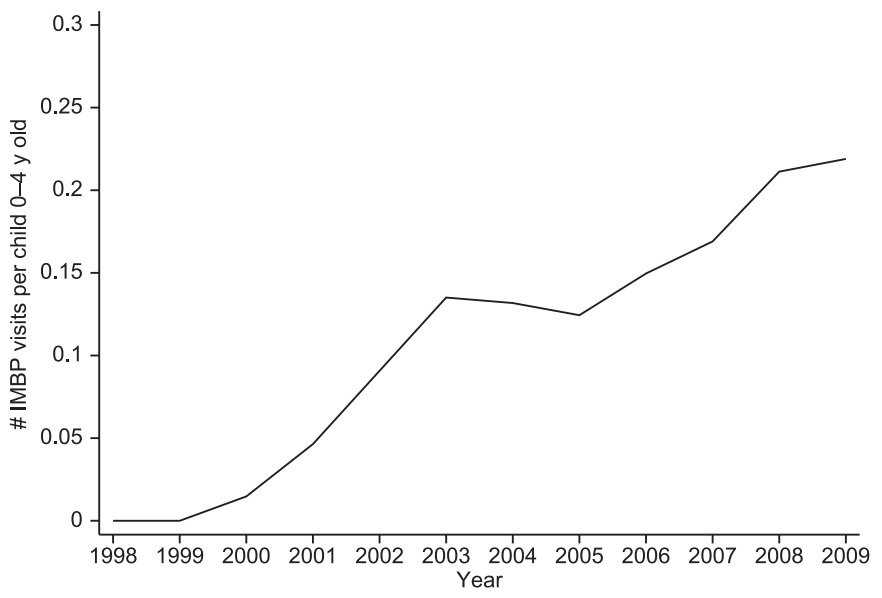

FIGURE 1

Annual average number of IMBP visits per child aged 0 to 4 years per county.

average number of IMBP visits per county by $500,1000,2000$, and 4000 visits led to corresponding predicted reductions in school-level average number dmft per kindergarten student of 0.03 , $0.04,0.06$, and 0.09, respectively, compared with actual 2009 values.

Schools that had $80 \%$ or more students participating in the NSLP had a higher school-level average dmft score than the full sample of schools (Table 3 ). In this subgroup, the school-level average dmft was 1.77. Assuming no IMBP implementation in 2009, predicted average dmft was 1.79 (95\% Cl, 1.68 to 1.90).
Increasing the mean number of IMBP visits per county led to corresponding predicted reductions in mean dmft per kindergarten student of 0.05, 0.06, 0.07, and 0.12 .

\section{DISCUSSION}

Surveillance information presented in this study suggests that the prevalence of dental caries in primary teeth of children in North Carolina increased slightly in the first few years of the 2000s, then started to decline around the middle of the decade and continued through the end of the observation period for this study. Against these secular trends in dental caries, we sought to determine whether the annual increase in IMBP visits since 2000 is associated with the observed improvement in oral health that began in the mid-2000s. We found that the increase in IMBP visits for Medicaidenrolled children was associated with a small but statistically significant reduction in dmft scores among kindergarten students in the state.

The magnitude of the population impact of the IMBP is determined by the exposure rate for preventive dental services in the overall population and the magnitude of the effect of the intervention among those exposed. Evidence suggests that the IMBP is sufficiently widespread and effective enough to have a measurable effect on the oral health of preschool-aged children. The number of Medicaid children 0 to 3 years of age and thus those who are eligible for IMBP services has increased faster than the population of children $<5$ years of age, the denominator used for this analysis. The increase was from $29 \%$ of the preschool population in 2001 to $42 \%$ in 2009, a sizable increase in the proportion of the population. Use of

TABLE 2 Adjusted Coefficients From Multivariate Regression Model Examining Effect of the IMBP on the Mean Number of dmft per Kindergarten Student per School

\begin{tabular}{|c|c|c|}
\hline Variable & All Schools $(N=1294)$ & $\begin{array}{l}\text { Only Schools That Had } \geq 80 \% \text { of } \\
\text { Students Participate in NSLP } \\
\text { During at Least } 1 \text { y }(N=448)\end{array}$ \\
\hline Mean number of IMBP visits per child aged $0-4$ y per county (lagged 3 y, to age 2) & $\begin{array}{c}-0.248^{\star \star} \\
(-0.401 \text { to }-0.096)\end{array}$ & $\begin{array}{c}-0.320^{\star \star} \\
(-0.553 \text { to }-0.087)\end{array}$ \\
\hline Number of dentists per 10000 population per county & $\begin{array}{c}0.035^{\star} \\
(0.002 \text { to } 0.068)\end{array}$ & $\begin{array}{c}0.038 \\
(-0.026 \text { to } 0.103)\end{array}$ \\
\hline Number of primary care physicians per 10000 population per county & $\begin{array}{c}-0.016^{\star} \\
(-0.029 \text { to }-0.002)\end{array}$ & $\begin{array}{c}-0.007 \\
(-0.031 \text { to } 0.018)\end{array}$ \\
\hline Percentage of children aged 0-19 y Medicaid eligible per county & $\begin{array}{c}0.010^{\star \star \star} \\
(0.005 \text { to } 0.015)\end{array}$ & $\begin{array}{c}0.024^{\star \star \star} \\
(0.015 \text { to } 0.034)\end{array}$ \\
\hline Percentage of students participating in NSLP per school & $\begin{array}{c}0.004^{\star \star \star} \\
\text { (0.002 to } 0.006)\end{array}$ & $\begin{array}{c}0.002 \\
(-0.001 \text { to } 0.004)\end{array}$ \\
\hline Percentage of kindergarten students who are Hispanic per school & $\begin{array}{c}0.018^{\star \star \star} \\
(0.015 \text { to } 0.020)\end{array}$ & $\begin{array}{c}0.017^{\star \star \star} \\
(0.013 \text { to } 0.020)\end{array}$ \\
\hline Intercept & $\begin{array}{c}0.879^{\star \star \star} \\
(0.671 \text { to } 1.088)\end{array}$ & $\begin{array}{c}0.711^{\star \star \star} \\
(0.310 \text { to } 1.111)\end{array}$ \\
\hline Adjusted $R^{2}$ & 0.685 & 0.604 \\
\hline
\end{tabular}

Cluster-robust SEs adjusted for potential correlation between schools' errors over time. $95 \% \mathrm{Cl}$ in parentheses.

${ }^{\star} P<.05 ;{ }^{\star \star} P<.01 ;{ }^{* \star \star} P<.001$. 


\begin{tabular}{|c|c|c|c|c|c|c|}
\hline & 2009 Actual Values & No IMBP Implementation & $\begin{array}{l}+500 \text { Visits } \\
\text { per County }\end{array}$ & $\begin{array}{l}\text { +1000 Visits } \\
\text { per County }\end{array}$ & $\begin{array}{l}+2000 \text { Visits } \\
\text { per County }\end{array}$ & $\begin{array}{l}+4000 \text { Visits } \\
\text { per County }\end{array}$ \\
\hline \multicolumn{7}{|l|}{ Input values for predictions } \\
\hline Mean number of IMBP visits per county & 2823 & 0 & 3323 & 3823 & 4823 & 6823 \\
\hline Mean number of children aged $0-4$ y per county & 15315 & 15315 & 15315 & 15315 & 15315 & 15315 \\
\hline $\begin{array}{l}\text { Mean number of IMBP visits per child aged 0-4 y } \\
\text { per county }\end{array}$ & 0.18 & 0 & 0.22 & 0.25 & 0.31 & 0.45 \\
\hline \multicolumn{7}{|l|}{ State-level measures } \\
\hline Total number of IMBP visits & 132658 & 0 & 182658 & 232658 & 332658 & 532658 \\
\hline Total number of eligible children aged $1-3$ y & 176313 & 176313 & 176313 & 176313 & 176313 & 176313 \\
\hline $\begin{array}{l}\text { Total number of IMBP visits per eligible } \\
\text { child aged } 1-3 \text { y }\end{array}$ & 0.75 & 0 & 1.04 & 1.32 & 1.89 & 3.02 \\
\hline \multicolumn{7}{|l|}{ Predictions of mean $\mathrm{dmft}$} \\
\hline Mean dmft $(95 \% \mathrm{Cl})$ & 1.423 & $\begin{array}{c}1.45 \\
(1.39 \text { to } 1.50)\end{array}$ & $\begin{array}{c}1.391 \\
(1.34 \text { to } 1.44)\end{array}$ & $\begin{array}{c}1.383 \\
(1.34 \text { to } 1.43)\end{array}$ & $\begin{array}{c}1.368 \\
(1.32 \text { to } 1.42)\end{array}$ & $\begin{array}{c}1.334 \\
(1.27 \text { to } 1.40)\end{array}$ \\
\hline $\begin{array}{l}\text { Mean } \mathrm{dmft} \text { in schools with } \geq 80 \% \text { students eligible } \\
\text { for NSLP }(95 \% \mathrm{Cl})\end{array}$ & 1.766 & $\begin{array}{c}1.791 \\
(1.68 \text { to } 1.90)\end{array}$ & $\begin{array}{c}1.720 \\
(1.63 \text { to } 1.82)\end{array}$ & $\begin{array}{c}1.711 \\
(1.62 \text { to } 1.81)\end{array}$ & $\begin{array}{c}1.692 \\
(1.60 \text { to } 1.79)\end{array}$ & $\begin{array}{c}1.647 \\
(1.54 \text { to } 1.76)\end{array}$ \\
\hline $\begin{array}{l}\text { Cumulative change in mean dmft over next } 5 \mathrm{y} \\
\text { in all schools }\end{array}$ & & 0.135 & -0.161 & -0.199 & -0.273 & -0.447 \\
\hline $\begin{array}{l}\text { Cumulative change in mean dmft over next } 5 \text { y } \\
\text { in schools with } \geq 80 \% \text { students eligible for NSLP }\end{array}$ & & 0.125 & -0.228 & -0.276 & -0.372 & -0.596 \\
\hline
\end{tabular}

preventive dental services provided through the IMBP by children $<3$ years of age quickly expanded from only 40 counties when the program was first implemented to all 100 counties. ${ }^{14}$ By the end of the study period in 2009, more than 130000 preventive dental visits were occurring in a little more than $40 \%$ of well child visits for 1 - to 3-year-olds.

The delivery of a comprehensive set of preventive dental services in primary medical care is a new idea, but evidence has emerged demonstrating its effectiveness in improving pediatric oral health. Currently 46 state Medicaid programs reimburse physicians for some preventive dental services, most having adopted the policy since 2006. ${ }^{31}$ Fluoride varnish, which is recommended by the American Academy of Pediatrics ${ }^{32}$ and the US Preventive Services Task Force ${ }^{33}$ for use by physicians beginning as soon as the first tooth erupts, is the procedure most commonly reimbursed. Studies of the North Carolina program found that Medicaid-enrolled children who have at least 4 IMBP visits by 3 years of age have a $17 \%$ lower rate of dental caries-related treatments by 6 years of age compared with children with no visits. ${ }^{15}$ A systematic review by the Cochrane Collaboration of the available evidence from clinical trials produced a pooled preventive faction for dental caries of $0.33(95 \% \mathrm{Cl}, 0.19$ to 0.48$)$, leading it to conclude that fluoride varnish results in a substantial benefit for the primary dentition. ${ }^{34}$

We observed a positive association between the proportion of students in a school participating in the NSLP and the mean number of dmft per kindergarten student per school. This finding is consistent with individual-level studies in which children from low-income families have more dental disease than children from families with higher incomes. ${ }^{35-37}$ We found an increase of 3 percentage points in the effectiveness of the IMBP in high-risk schools compared with all schools. The larger effect of IMBP services in high-risk schools suggests that on average, children from low-income families are benefiting more from the IMBP than those from higher-income families. This strategy in which students who attend high-risk schools are targeted through their primary care medical offices before attending school should help reduce oral health disparities.

The regression-based predictions of IMBP effects are helpful for planning program expansions and enhancements. We estimated dmft changes with an increase in IMBP visits using 4 different scenarios, varying from a 1.38 -fold to a 4.02-fold increase in total number of visits over the 2009 value of 132658 . Estimated cumulative 5-year reductions in mean $\mathrm{dmft}$ for all schools varied from 0.16 to $0.60 \mathrm{dmft}$ per student per school with the different predictions. The maximum reduction in $\mathrm{dmft}$ requires increasing the average number of IMBP visits per eligible child from its current level of 0.75 to 3.02 per county. These simulations demonstrate that additional and substantial reductions in oral health disparities require that we not only continue to expand the successful IMBP in primary care but supplement it with dental caries prevention strategies implemented in other settings that reach families with young children with effective services. 38,39

The main limitation of this study is its ecologic design, in which IMBP exposure and $\mathrm{dmft}$ scores are aggregated at the 
group level. This design has been used extensively in public health and other disciplines but has known limitations. ${ }^{40,41}$ Variation of extraneous risk factors within or across groups can lead to confounding or effect modification by group. We controlled for major trends other than IMBP services that could contribute to confounding of the ecologic IMBP and dmft association, $2 \mathrm{im}$ portant sociodemographic changes in the North Carolina population (percentage Hispanic, percentage eligible for NSLP), and access to preventive dental services outside the medical office (dentists per population). We also controlled for time-invariant unobserved differences in schools through the use of school fixed effects and varying annual trends with year fixed effects.

The study is also subject to bias in the classification of exposures to IMBP services within groups. The total population of kindergarten students includes both children who are eligible for IMBP services and those who are not, and we do not know who received services. Exposures might have been misclassified by applying county-level mean IMBP participation rates to all schools in that county. Unlike individual studies, ecologic studies tend to bias results away from the null. However, our use of multiple time points to establish trends in mean IMBP exposure rates should help minimize this concern. We also found a larger effect but in the same direction among high-risk schools, where average population effects should not be diluted as much as with all schools because they have a larger percentage of students enrolled in Medicaid.

The predictions of dmft scores with different levels of preventive dental services must be interpreted with caution. The use of a regression line to make predictions outside the range of observed values of the explanatory variable may lead to biased estimates. However, the values for IMBP visits used to make the predictors and the observed outcomes seem reasonable, and this information is important in providing general insights into program planning.

\section{CONCLUSIONS}

We sought to determine the statewide, population-level impact of the IMBP, finding that the program has contributed to a downward trend in dental caries among North Carolina preschoolaged children. This intervention in medical offices appears to be widespread enough among high-risk populations and effective enough that its impact on the prevalence of dental caries can be detected at the population level. The effects of the IMBP are more pronounced among children in highrisk schools than among children attending lower-risk schools, leading us to conclude that the program is contributing to reductions in disparities in dental caries in preschool-aged populations. Regression-based predictions suggest that resolution of oral health disparities at the population level will require the integration of primary care services provided in the IMBP with other community- and practice-based strategies effective in reducing dental caries.

\section{REFERENCES}

1. Marcenes W, Kassebaum NJ, Bernabé E, et al. Global burden of oral conditions in 1990-2010: a systematic analysis. J Dent Res. 2013;92(7):592-597

2. US Department of Health and Human Services, Office of Disease Prevention and Health Promotion. 2013. Healthy People 2010 topic and objectives. Oral health. Available at: www. healthypeople.gov/2020/topicsobjectives2020/ overview.aspx?topicid=32. Accessed July 23, 2013

3. Dye BA, Arevalo 0, Vargas CM. Trends in paediatric dental caries by poverty status in the United States, 1988-1994 and 1999-2004. Int J Paediatr Dent. 2010;20(2):132-143

4. Beltrán-Aguilar ED, Barker LK, Canto MT, et al; Centers for Disease Control and Prevention (CDC). Surveillance for dental caries, dental sealants, tooth retention, edentulism, and enamel fluorosis-United States, 1988-1994 and 1999-2002. MMWR Surveill Summ. 2005;54(3):1-43
5. Sheiham A. Oral health, general health and quality of life. Bull World Health Organ. 2005;83(9):644

6. Casamassimo PS, Thikkurissy S, Edelstein $\mathrm{BL}$, Maiorini E. Beyond the dmft: the human and economic cost of early childhood caries. J Am Dent Assoc. 2009;140(6):650657

7. Abanto J, Carvalho TS, Mendes FM, Wanderley MT, Bönecker M, Raggio DP. Impact of oral diseases and disorders on oral health-related quality of life of preschool children. Community Dent Oral Epidemiol. 2011;39(2):105-114

8. Lee HH, Milgrom P, Starks H, Burke W. Trends in death associated with pediatric dental sedation and general anesthesia. Paediatr Anaesth. 2013;23(8):741-746

9. North Carolina Institute of Medicine Task Force on Dental Care Access. Report to the North Carolina General Assembly and to the Secretary of the North Carolina De- partment of Health and Human Services. Durham, NC: North Carolina Institute of Medicine; 1999. Available at: www.nciom. org/wp-content/uploads/NCIOM/docs/dentalrpt.pdf. Accessed July 23, 2013

10. North Carolina Institute of Medicine. 2005 Oral Health Summit Access to Dental Care: summit proceedings and action plan. Durham, NC: North Carolina Institute of Medicine; 2005. Available at: www.nciom.org/wp-content/ uploads/NCIOM/projects/dental/2005dentalupdate.pdf. Accessed July 23, 2013

11. North Carolina Institute of Medicine Task Force on Children's Preventive Oral Health Services. Cary, NC: North Carolina Institute of Medicine; 2013. Available at: www.nciom org/task-forces-and-projects/?task-force-onchildrens-preventive-oral-health-services. Accessed July 23, 2013

12. Rozier RG. Oral health in North Carolina: innovations, opportunities, and challenges. N C Med J. 2012;73(2):100-107 
13. Rozier RG, Sutton BK, Bawden JW, Haupt K, Slade GD, King RS. Prevention of early childhood caries in North Carolina medical practices: implications for research and practice. J Dent Educ. 2003;67(8):876-885

14. Rozier RG, Stearns SC, Pahel BT, Quinonez RB, Park J. How a North Carolina program boosted preventive oral health services for low-income children. Health Aff (Millwood). 2010;29(12):2278-2285

15. Pahel BT, Rozier RG, Stearns SC, Quiñonez RB. Effectiveness of preventive dental treatments by physicians for young Medicaid enrollees. Pediatrics. 2011;127(3). Available at: www.pediatrics.org/cgi/content/full/127/3/e682

16. Stearns SC, Rozier RG, Kranz AM, Pahel BT, Quiñonez RB. Cost-effectiveness of preventive oral health care in medical offices for young Medicaid enrollees. Arch Pediatr Adolesc Med. 2012;166(10):945-951

17. Rozier RG, King RS. Defining the need for dental care in North Carolina: contributions of public health surveillance of dental diseases and conditions. N C Med J. 2005;66(6):438-444

18. King RS, Satterfield WC, Rozier RG. A statewide system for dental caries in kindergarten children. J Dent Res. 1998; Abst. No. 946, 77 (Special Issue A): 224

19. Brickhouse TH, Rozier RG, Slade GD. Effects of enrollment in Medicaid versus the State Children's Health Insurance Program on kindergarten children's untreated dental caries. Am J Public Health. 2008;98(5):876881

20. Divaris K, Rozier RG, King RS. Effectiveness of a school-based fluoride mouthrinse program. J Dent Res. 2012;91(3):282-287

21. Beil H, Rozier RG, Preisser JS, Stearns SC, Lee JY. Effects of early dental office visits on dental caries experience [published online ahead of print October 17, 2013]. Am $J$ Public Health. doi: 10.2105/AJPH.2013.301325
22. North Carolina Department of Health and Human Services, Division of Medical Assistance. Quarterly reports for Into the Mouths of Babes Program, 2000-2012

23. US Department of Education, National Center for Education Statistics. Common Core of Data (CCD). Available at: http://nces. ed.gov/ccd/. Accessed June 26, 2013

24. North Carolina Department of Public Instruction, Division of Financial and Business Services. Free and reduced meals application data. 2013. Available at: www.ncpublicschools. org/fbs/resources/data/. Accessed July 24, 2013

25. U.S. Department of Agriculture, Food and Nutrition Service. Child nutrition programs: income eligibility guidelines, 2013. 2013. Available at: www.fns.usda.gov/cnd/governance/notices/ iegs/iegs.htm. Accessed July 24, 2013

26. Cecil G. Sheps Center for Health Services Research. North Carolina Health Professions Data System, 2012. Available at: www. shepscenter.unc.edu/hp/. Accessed February 24, 2012

27. North Carolina Department of Health and Human Services, Division of Medical Assistance. Authorized Medicaid and Health Choice for Children eligibles reports. Available at: www. ncdhhs.gov/dma/elig/. Accessed July 24, 2013

28. North Carolina State Center for Health Statistics. North Carolina population estimates. Available at: www.schs.state.nc.us/SCHS/ data/population/nchspop.cfm. Accessed July 24, 2013

29. Wooldridge JM. Advanced panel data methods. In: Introductory Econometrics: A Modern Approach. 4th ed. Chapter 14. Independence, KY: Cengage Learning; 2009

30. Cameron AC, Trivedi PK. Linear panel-data models: basics. In: Microeconomics Using Stata. Chapter 8. College Station, TX: Stata Press; 2009:240-253

31. Sams LD, Rozier RG, Wilder RS, Quinonez RB. Adoption and implementation of poli- cies to support preventive dentistry initiatives for physicians: a national survey of Medicaid programs. Am J Public Health. 2013;103(8):e83-e90

32. Section on Pediatric Dentistry and Oral Health. Preventive oral health intervention for pediatricians. Pediatrics. 2008;122(6): 1387-1394

33. US Preventive Services Task Force. Prevention of dental caries in preschoolaged children. 2004. Available at: www. uspreventiveservicestaskforce.org/uspstf/ uspsdnch.htm. Accessed July 29, 2013

34. Marinho VC, Higgins JP, Logan S, Sheiham A. Fluoride varnishes for preventing dental caries in children and adolescents. Cochrane Database Syst Rev. 2002;(3):CD002279

35. Dye BA, Li X, Thorton-Evans G. Oral health disparities as determined by selected Healthy People 2020 oral health objectives for the United States, 2009-2010. NCHS Data Brief. 2012;Aug(104):1-8

36. da Fonseca MA. The effects of poverty on children's development and oral health. Pediatr Dent. 2012;34(1):32-38

37. Clark BJ, Graves RC, Webster DB, Triol CW. Caries and treatment patterns in children related to school lunch program eligibility. J Public Health Dent. 1987;47(3):134-138

38. Hirsch GB, Edelstein BL, Frosh M, Anselmo T. A simulation model for designing effective interventions in early childhood caries. Prev Chronic Dis. 2012;9:E66

39. Association of State and Territorial Dental Directors. Best practices approach: prevention and control of early childhood tooth decay. February 2013. Available at: www.astdd. org/docs/BPAEarlyChildhood.pdf. Accessed October 10, 2013

40. Greenland S, Morgenstern H. Ecological bias, confounding, and effect modification. Int J Epidemiol. 1989;18(1):269-274

41. Wakefield J. Ecologic studies revisited. Annu Rev Public Health. 2008;29:75-90 